pathway during clinical cardiopulmonary bypass. Circulation. 1996;93:2014-8.

3. Casati V, Gerli C, Franco A, Della Valle P, Benussi S, Alfieri O, et al. Activation of coagulation and fibrinolysis during coronary surgery. On-pump versus off-pump techniques. Anesthesiology. 2001;95:1103-9.

4. Casati V, Della Valle P, Benussi S, Franco A, Gerli C, Baili P, et al. Effects of tranexamic acid on postoperative bleeding and related hematochemical variables in coronary surgery: comparison between on-pump and offpump techniques. J Thorac Cardiovasc Surg. 2004;128:83-91.

5. Englberger L, Immer FF, Eckstein FS, Berdat PA, Haeberli A, Carrel TP. Off-pump coronary artery bypass operations does not increase procoagulant and fibrinolytic activity: preliminary results. Ann Thorac Surg. 2004; 77:1560-6.

6. Poston R, Gu J, Brown J, Gammie J, White $\mathrm{C}$, Manchio J, et al. Hypercoagulability affecting early vein graft patency does not exist after off-pump coronary artery bypass. $J$ Cardiothorac Vasc Anesth. 2005;19:11-8.

doi:10.1016/j.jtcvs.2006.04.047

\section{Reply to the Editor:}

Thank you for the invitation to respond to Dr Casati and colleagues' letter. We used an in vitro bleeding time test (Platelet Function Analyzer [PFA]-100) to evaluate platelet function perioperatively at 7 different observation times. Only one of these observations was performed during cardiopulmonary bypass with hemodiluted patients. Fibrinolytic activity can indirectly be measured, evaluating the balance between the promoter of fibrinolysis (tissuetype plasminogen activator) and its inhibitor (plasminogen activator inhibitor 1). In our study ${ }^{1}$ we observed that tissue-type plasminogen activator levels are not increased, whereas plasminogen activator inhibitor 1 and D-dimer levels are modestly increased after off-pump coronary artery bypass (OPCAB) surgery. These data would suggest that fibrinolysis is not particularly activated during OPCAB surgery. Dr Casati states that an antifibrinolytic agent should be used in patients undergoing OPCAB surgery because he has previously demonstrated ${ }^{2}$ a significant reduction of postoperative bleeding in patients undergoing OPCAB treated with tranexamic acid (25 patients) compared with patients undergoing OPCAB treated with placebo (25 patients). In their study Casati and colleagues ${ }^{2}$ were not able to show a significant difference in blood product transfusion between the groups. Moreover, hemoglobin and hematocrit values reported up to 24 hours postoperatively were not influenced by tranexamic acid administration. As we remarked in our article, recent studies with angiographic control have shown a worse graft patency in patients operated on by means of the OPCAB technique compared with those undergoing the on-pump technique. Inaccurate anastomosis rather than a procoagulative state is probably the main cause of these results; nevertheless, this has not been proved. Although numerous investigators have documented profound short-term and midterm coagulativefibrinolytic and inflammatory alterations in patients undergoing coronary artery bypass grafting surgery, there are no clinical studies that evaluated prospectively and on an appropriate number of patients the value of prothrombotic and proinflammatory markers in predicting early graft occlusion. Existing studies are small and produced conflicting results: Poston and associates ${ }^{3}$ reported that thrombelastography and whole blood aggregometry do not predict graft occlusion; however, in another study the same authors showed a reduction in platelet sensitivity to aspirin by means of both thrombelastography and aggregometry in patients with early graft failure. ${ }^{4}$ Karski and coworkers ${ }^{5}$ have recently demonstrated that tranexamic acid administration does not worsen early saphenous graft patency in patients receiving on-pump coronary artery bypass grafting. However, our results show that in the first 24 hours after the operation, patients undergoing onpump operations and OPCAB have a different activation of the coagulation and fibrinolytic systems. Consequently, what is safe for patients undergoing on-pump operations might not be safe for those undergoing OPCAB. The reason why we operate on patients with coronary artery disease is to improve their long-term outcome while trying to minimize their perioperative risk. Considering that postoperative bleeding is not a serious complication after OPCAB surgery, we agree with Dr Casati's final remarks: "Further randomized studies, enrolling larger numbers of patients, are needed to confirm the antiinflammatory effects of TA and to rule out the potential risk of thrombotic complications.",2

Domenico Paparella, MD Antonella Galeone, MD Giuseppe Scrascia, MD Division of Cardiac Surgery University of Bari
Piazza Giulio Cesare 11

Bari 70100

Italy

E-mail: paparella@tin.it

\section{References}

1. Paparella D, Galeone A, Venneri MT, Coviello M, Scrascia G, Marraudino N, et al. Activation of the coagulation system during coronary artery bypass grafting operation: comparison between on pump and off pump techniques. J Thorac Cardiovasc Surg. 2006; 131:290-7.

2. Casati V, Della Valle P, Benussi S, Franco A, Gerli C, Baili P, et al. Effects of tranexamic acid on postoperative bleeding and related hematochemical variables in coronary surgery: comparison between on-pump and offpump techniques. J Thorac Cardiovasc Surg. 2004;128:83-91.

3. Poston R, Gu J, Brown J, Gammie J, White $\mathrm{C}$, Manchio J, et al. Hypercoagulability affecting early vein graft patency does not exist after off-pump coronary artery bypass. $J$ Cardiothorac Vasc Anesth. 2005;19:11-8.

4. Poston R, Gu J, Manchio J, Lee A, Brown $\mathrm{J}$, Gammie J, et al. Platelet function tests predict bleeding and thrombotic events after off-pump coronary bypass grafting. Platelet function tests predict bleeding and thrombotic events after off-pump coronary bypass grafting. Eur J Cardiothorac Surg. 2005;27:584-91

5. Karski J, Djaiani G, Carroll J, Iwanochko M, Seneviratne P, Liu P, et al. Tranexamic acid and early saphenous vein graft patency in conventional coronary artery bypass graft surgery: a prospective randomized controlled clinical trial. J Thorac Cardiovasc Surg. 2005;130:309-14.

doi:10.1016/j.jtcvs.2006.05.043

\section{A new surgical paradigm: Hybrid open and endovascular repair of the ascending aorta and aortic arch for acute type $A$ dissection \\ To the Editor:}

I read with interest the editorial by Dobrilovic and Elefteriades ${ }^{1}$ reflecting on the potential future application of simultaneous hybrid endoluminal graft repair of the descending thoracic aorta after traditional open surgical repair of the ascending aorta and aortic arch for acute type A aortic dissection, as discussed in the article by Uchida and associates. ${ }^{2}$

Although the results reported by Uchida and associates ${ }^{2}$ are noteworthy, stabilizing the true lumen in the descending thoracic aorta with an endoluminal graft after total aortic arch replacement may not be the final, or best, approach for acute type A aortic dissection. The current surgical paradigm is 
to treat the ascending aortic and arch pathology in the standard open surgical fashion and follow the progression of the descending thoracic aorta. As Dobrilovic and Elefteriades ${ }^{1}$ expertly point out, expansion of the descending thoracic aorta after acute type A dissection may be a slow process. There may, however, be additional reasons to consider simultaneous hybrid repair in this situation.

Total arch replacement involves the use of deep hypothermic circulatory arrest (DHCA). The increased risks associated with this technique have been well documented, and eliminating DHCA for the treatment of acute Type A aortic dissections would potentially make this a safer and better tolerated procedure. Another alternative hybrid approach would be to repair the entry point tear in the ascending aorta with standard open surgical techniques (interposition graft or ascending conduit) and simultaneously bypass the great vessels with grafts off the newly completed ascending aortic graft. Simultaneous deployment of an endoluminal graft in an antegrade fashion through the ascending graft, across the aortic arch, and into the proximal descending thoracic aorta would accomplish a total arch reconstruction without the need for DHCA. ${ }^{3}$ This approach maximizes the advantages of endovascular technologies by making a complex procedure less invasive while stabilizing the true lumen of the descending thoracic aorta. We have shown that stabilizing the true lumen in the descending thoracic aorta is an active process that in time leads to progressive expansion of the true lumen and continued thrombosis of the false lumen. ${ }^{4}$ In addition to potentially preventing future complications and need for reoperation, stabilization of the true lumen and continued active true lumen expansion after thoracic endografting can potentially improve distal organ perfusion.

Hybrid approaches to complex aortic pathologies may allow us to offer surgical repair to patients with acute type A aortic dissection who might not otherwise tolerate DHCA. The less invasive advantages of simultaneous arch exclusion with an endoluminal graft after great vessel transposition could accelerate patient recovery and provide the added potential advantage of distal true lumen stabilization. I therefore believe that the surgical paradigm may be shifting toward hybrid approaches, not away from them.
Grayson H. Wheatley III, MD

Arizona Heart Institute

Phoenix, Ariz

\section{References}

1. Dobrilovic N, Elefteriades JA. Stenting the descending aorta during repair of type A dissection: technology looking for an application? J Thorac Cardiovasc Surg. 2006;131:777-8.

2. Uchida N, Ishihara H, Shibamura H, Kyo Y, Ozawa M. Midterm results of extensive primary repair of the thoracic aorta by means of total arch replacement with open stent graft placement for an acute type A aortic dissection. J Thorac Cardiovasc Surg. 2006;131:862-7.

3. Diethrich EB, Ghazoul M, Wheatley GH, Alpern J, Rodriguez-Lopez J, Ramaiah V, et al. Surgical correction of ascending type a thoracic aortic dissection: simultaneous endoluminal exclusion of the arch and distal aorta. $J$ Endovasc Ther. 2005;12:660-6.

4. Nathanson DR, Rodriguez-Lopez JA, Ramaiah VG, Williams J, Olsen DM, Wheatley $\mathrm{GH}$, et al. Endoluminal stent-graft stabilization for thoracic aortic dissection. $J$ Endovasc Ther. 2005;12:345-9.

$$
\text { doi:10.1016/j.jtcvs.2006.04.043 }
$$

\section{Reply to the Editor:}

We appreciate the thoughtful commentary from Dr Wheatley. We are aware of the imaginative work being done in catheterbased treatment of aortic diseases at the Arizona Heart Institute.

There are certainly many clever ways to "manipulate" the anatomy of the aortic arch to make stent therapy feasible, and we applaud the exploration of these techniques. We disagree, however, with the undercurrent of fear of deep hypothermic circulatory arrest (DHCA) manifest in Dr Wheatley's letter.

DHCA is a proven modality in aortic surgery, with a vast clinical experience demonstrating its clinical utility and safety. ${ }^{1-4}$ At our own institution, Dr Arjet Gega has just completed (for upcoming submission) a review of 400 patients operated on under "straight" DHCA, without any adjunctive retrograde or antegrade cerebral perfusion. This experience included all comers: ascending, arch, descending, and thoracoabdominal; elective and emergency; and ruptured and nonruptured. Overall mortality was $6.5 \%$, stroke rate was $4.9 \%$, and reexploration for bleeding was $3.9 \%$. Cerebral protection was excellent, with most strokes embolic in origin. The supposed bleeding diathesis of DHCA is simply not a problem. It is not uncommon for us to find the morning's DHCA patient extubated, vi- brantly conversant, and having a light supper by the time of evening rounds. DHCA need not be feared. At our institution we marvel at the protective abilities of this technique, and we are pleased to call upon them at every opportunity.

Current results for surgery under DHCA at many expert centers worldwide sets a standard that will be hard to exceed with clever extra-anatomic and catheter based modalities. In fact, it remains to be shown in careful analysis of large clinical series that the alternative modalities can even come close to meeting the excellent results of traditional, direct arch surgery under DHCA.

John A. Elefteriades, MD Nikola Dobrilovic, MD Arjet Gega, MD

Department of Cardiothoracic Surgery Yale University School of Medicine New Haven, Conn

\section{References}

1. Minatoya K, Ogino H, Matsuda H, Sasaki H, Yagihara T, Kitamara S. Surgical management of distal arch aneurysm: another approach with improved results. Ann Thorac Surg. 2006;81:1353-7.

2. Appoo JJ, Augoustides JG, Pochettino A, Savino JS, McGarvey ML, Cowie DC, et al. Perioperative outcome in adults undergoing elective deep hypothermic circulatory arrest with retrograde cerebral perfusion in proximal aortic arch repair: evaluation of protocolbased care. J Cardiothorac Vasc Anesth. 2006;20:3-7.

3. Svensson LG, Nadolny EM, Penney DL, Jacobson J, Kimmel WA, Entrup MH, et al. Prospective randomized neurocognitive and S-100 study of hypothermic circulatory arrest, retrograde brain perfusion, and antegrade brain perfusion for aortic arch operations. Ann Thorac Surg. 2001;71:1905-12.

4. Goldstein LJ, Davies RR, Rizzo JA, Davila JJ, Cooperberg MR, Shaw RK, et al. Stroke in surgery of the thoracic aorta: incidence, impact, etiology, and prevention. J Thorac Cardiovasc Surg. 2001;122:935-45. doi:10.1016/j.jtcvs.2006.05.020

\section{When less is more: Go slowly when repopulating a decellularized valve in vivo!}

To the Editor:

We read with interest the recent article by Juthier and colleagues ${ }^{1}$ describing the effects of granulocyte colony-stimulating factor (GCSF) on decellularized xenogenic heart valves implanted in systemic circulation in sheep. The hypothesis was tested 